\title{
Impact of Kidney Function on Cardiovascular Risk and Mortality: A Comparison of South Asian and European Cohorts
}

\author{
Sophie V. Eastwood ${ }^{\mathrm{a}}$ Nishi Chaturvedi ${ }^{\mathrm{a}}$ Naveed Sattar ${ }^{\mathrm{b}}$ Paul I. Welsh ${ }^{\mathrm{b}}$ \\ Alun D. Hughes ${ }^{a}$ Therese Tillin ${ }^{a}$ \\ ${ }^{\mathrm{a}}$ Institute of Cardiovascular Science, University College London, London, UK; ${ }^{\mathrm{b}}$ Institute of Cardiovascular and \\ Medical Sciences, University of Glasgow, Glasgow, UK
}

\section{Keywords}

Ethnic differences - Cardiovascular disease - Mortality .

Estimated glomerular filtration rate $\cdot$ Urinary

albumin-creatinine ratio

\begin{abstract}
Background: Evidence is limited on ethnic differences in associations between kidney function markers and mortality or cardiovascular disease (CVD). Methods: Baseline crosssectional analysis and longitudinal follow-up study of a UK population-based cohort of 1,116 Europeans and 1,104 South Asians of predominantly Indian descent, age $52 \pm$ 7 years at baseline (1988-1991). Kidney function was estimated using Cystatin C and creatinine-based chronic kidney disease (CKD) Epidemiology Collaboration estimated glomerular filtration rate (eGFR) equations, and urinary albumin-creatinine ratio (ACR). Mortality was captured at 27 years, and incident CVD at 22 years, from death certification, medical records and participant report. Longitudinal associations between eGFR/ACR and mortality/incident CVD were examined using Cox models. Results: eGFR $\mathrm{R}_{\text {cys }}$ was lower and ACR higher in South Asians than Europeans. eGFR and eGFR $\mathrm{R}_{\text {creat }}$ were more strongly associated with outcomes in Europeans than South Asians. Conversely, associations be-
\end{abstract}

tween ACR and outcomes were greater in South Asians than Europeans, for example, for CVD mortality: HRs $(95 \% \mathrm{Cl})$ adjusted for CVD risk factors and ACR/eGFR cys as appropriate, $p$ for ethnicity interaction: eGFR cys: Europeans: 0.76 (0.620.92), South Asians: 0.92 (0.78-1.07), $p=0.05$, eGFR creat: Europeans 0.81 (0.67-0.99), South Asians 1.18 (0.97-1.41), $p=$ 0.002, ACR: Europeans: 1.24 (1.08-1.42), South Asians: 1.39 $(1.25-1.57), p=0.23$. Addition of all CKD measures to a standard CVD risk factor model modestly improved prediction capability in Europeans; in South Asians only ACR contributed to improvement. Conclusions: Strong associations between ACR and outcomes in South Asians of predominantly Indian origin, and null associations for $\mathrm{eGFR}_{\text {cys }}$ and eGFR $\mathrm{Great}_{\text {, }}$ suggest that ACR may have greater utility in CVD risk prediction in South Asians. Further work is needed to validate these findings.

(c) 2019 The Author(s)

Published by S. Karger AG, Basel

\section{Introduction}

Chronic kidney disease (CKD), an established risk factor for all-cause mortality and cardiovascular disease (CVD) [1,2], has an adult prevalence of 5\% [3]. People of South Asian ancestry (from the Indian subcontinent)

\begin{tabular}{ll}
\hline KARGER & $\begin{array}{l}\text { ( } 2019 \text { The Author(s) } \\
\text { Published by S. Karger AG, Basel }\end{array}$ \\
E-Mail karger@karger.com & $\begin{array}{l}\text { This article is licensed under the Creative Commons Attribution } 4.0 \\
\text { International License (CC BY) (http://www.karger.com/Services/ } \\
\text { OpenAccessLicense). Usage, derivative works and distribution are } \\
\text { permitted provided that proper credit is given to the author and the } \\
\text { original publisher. }\end{array}$
\end{tabular}

Dr. Sophie V. Eastwood Clinical Research Fellow MRC Unit for Lifelong Health and Ageing at UCL 5th Floor, 1-19 Torrington Place, London, WC1E 7HB (UK) E-Mail sophie.eastwood@ucl.ac.uk 
Fig. 1. Follow-up of the SABRE cohort, 1988-2011. ACR, albumin-creatinine ratio; CVD, cardiovascular disease.

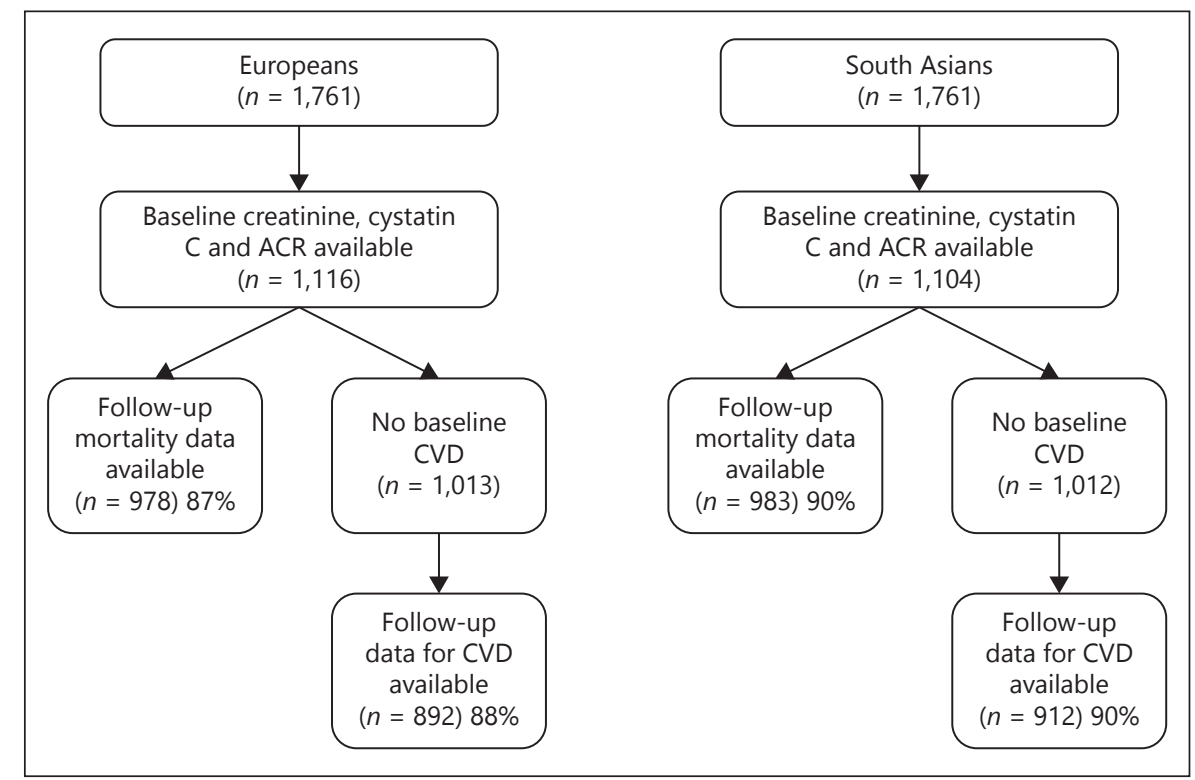

constitute the largest UK ethnic minority group [4] and the fastest growing migrant group in the USA [5]. Most studies report similar estimated glomerular filtration rate (eGFR) levels in Europeans and South Asians [6-10], despite the striking surfeit of CVD and end stage kidney disease in the latter group [11-14].

Data on longitudinal associations between CKD and mortality or CVD in South Asians are limited and contradictory. To our knowledge, only 2 studies have reported South Asian ethnicity-specific associations between eGFR, albuminuria and mortality and/or CVD; one found no ethnic differences [8], while an earlier analysis in the Southall and Brent Revisited (SABRE) study described stronger associations in South Asians than Europeans for albuminuria; however data on eGFR were not reported and event numbers at that stage were relatively low [14]. For the sole study reporting on eGFR, use of creatinine-based eGFR estimating equations may be biased [8], given creatinine is related to diet and muscle mass, both of which often vary considerably between South Asian and European populations [15, 16]. Therefore eGFR equations based on Cystatin C [17] are considered preferable for use in non-white ethnic groups [18], but to our knowledge, no study has examined how cystatin C-based eGFR relates to mortality or CVD outcomes in South Asians.

Using data from a UK community-based cohort of European and South Asian origin, our objectives were to study ethnic differences in (a) mid-life distributions of CKD markers and (b) longitudinal associations between
CKD markers and 26-year mortality and 20-year CVD morbidity. There were insufficient end stage renal disease events for analysis.

\section{Materials and Methods}

The SABRE study is a multi-ethnic cohort study; details are published elsewhere [19]. In brief, participants aged 40-69 years at baseline (1988-1991) were randomly selected from primary care physician lists and workplaces in north-west London. South Asian participants were first-generation migrants originating from the Indian subcontinent and were recruited in Southall only. European participants (largely UK-born) were recruited from both Southall and Brent. Stored blood samples were available only for participants recruited in Southall. Participants were followed for death, hospitalization, and primary care consultations from baseline to 2015 (mortality) or 2011 (morbidity). We report findings from the subset of 1,116 European and 1,104 South Asian men and women who had baseline stored blood samples and urinary albumin-creatinine ratio (ACR; Fig. 1).

At baseline, participants attended clinic for a series of measurements and completed a health and lifestyle questionnaire. This study uses measurements from baseline only. Creatinine and cystatin $\mathrm{C}$ were measured in stored serum samples by an automated clinically validated platform (c311, Roche Diagnostics, Burgess Hill, UK) using the manufacturer's calibrators and quality control material. Coefficient of variation of the serum assays was $<3.5 \%$. Renal function was quantified by (i) CKD Epidemiology Collaboration (CKD-EPI) eGFR estimating equations based on serum cystatin C ( $\mathrm{eGFR}_{\text {cys }}$, online suppl. Table S1; for all online suppl. material, see www.karger.com/doi/10.1159/000503873) [17], as these may give more accurate results in people of non-European ethnicity $[18,20]$, are less influenced by dietary patterns and differences in muscle mass than creatinine-based equations [21], and have a 
higher specificity for disease outcomes than creatinine-based measures [22], (ii) eGFR from CKD-EPI-creatinine equations $\left(\right.$ eGFR $_{\text {creat }}$, online suppl. Table S1) [17] and (iii) ACR. We also used eGFR from the Modification of Diet in Renal Disease (MDRD)

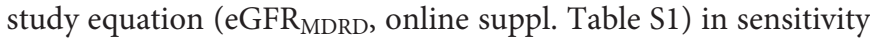
analyses [23]. Urine ACR was measured at baseline using a highly sensitive immunoturbidimetric method [24] with goat anti-human albumin antisera (Sanofi Diagnostics, Pasteur, Chaska, MN, USA) and human serum albumin standards (ORHA 20/21 grade HAS; Behring Diagnostics, Hoechst, UK). Timed overnight urine collections were also performed in a subset of 915 Europeans and 862 South Asians to enable calculation of albumin excretion rate (AER). Urine was tested to identify urinary tract infection; participants with positive test results were asked to provide repeat samples. Microalbuminuria was defined as an ACR of 3-30 mg/ mmol. Physician diagnosis or World Health Organization 1999 criteria for fasting and oral glucose tolerance test blood glucose measurements defined diabetes mellitus [25]. Antihypertensive use was ascertained by receipt of drugs in one of the following classes: ACE inhibitors, beta-blockers, CCBs, thiazides and other diuretics, reflecting contemporaneous use.

Deaths up to 2015 were flagged by the Office for National Statistics, and cause of death obtained from death certification (see below). Incident CVD was defined as coronary heart disease (CHD) and/or stroke up to 2011, from the following sources:

(1) From death certification (provided by NHS Digital on behalf of the Office for National Statistics). Cause of death included any of the following for CHD: angina, myocardial infarction or its sequelae, or atherosclerotic heart disease using International Classification of Disease-Ninth Edition (ICD-9) codes 410 through 415 or ICD-Tenth Edition (ICD-10) codes I200 through I259. For stroke, cause of death included ICD-9 codes 430 through 439 or ICD-10 codes I600 through I698.

(2) Primary care data were reviewed independently by 2 senior physicians blinded to participant ethnicity and identity. A CHD event was identified if both physicians agreed on definite or probable diagnosis of myocardial infarction or acute coronary syndrome, according to pre-determined criteria used in the AngloScandinavian Cardiac Outcomes Trial [26], based on symptoms, cardiac enzymes, electrocardiography findings, and hospital discharge diagnosis. Adjudication by a third physician was conducted if required. Coronary interventions (coronary artery bypass graft, angioplasty, stenting) were included as incident $\mathrm{CHD}$ events, as was angina confirmed on exercise testing. For stroke, primary care data were reviewed in a similar manner to $\mathrm{CHD}$, with definite or probable diagnosis of stroke made according to pre-determined criteria based on symptoms, duration of symptoms, and magnetic resonance imaging or computed tomography imaging.

(3) Hospital Episode Statistics (provided by NHS Digital [formerly the Health and Social Care Information Centre]), using the following diagnostic codes for CHD: ICD-9: 410-415, ICD-10: I200-I259, and/or procedures pertaining to coronary revascularization interventions or rehabilitation for ischemic heart disease, codes: K401-K469, K491-K504, K751-K759, U541 and the following for stroke: (ICD-9: 430-439, ICD-10: I600-I698).

(4) Participant report of physician-diagnosed stroke and duration of symptoms in excess of $24 \mathrm{~h}$.

CHD or stroke that occurred before baseline was identified from participant report (at baseline) of physician-diagnosed dis- ease (or presence of major Q waves on baseline electrocardiography for CHD).

All participants gave written informed consent. Approval for the baseline study was obtained from Ealing, Hounslow and Spelthorne, Parkside and University College London research Ethics Committees, and at follow-up from Fulham Local Research Ethics Committee (reference: 07/HO712/109).

\section{Statistical Analysis}

Baseline characteristics were compared by ethnicity and follow-up status; logistic and linear regression models determined age- and sex-adjusted differences. Classification of CKD stage by either $\mathrm{eGFR}_{\text {cys }}$ or $\mathrm{eGFR}_{\text {creat }}$ was compared, and cross-tabulated with ACR stages for each ethnic group [20]. ACR rather than AER was used in analyses to maximize power and comparability with other studies. For both Europeans and South Asians, longitudinal associations between standardized $\mathrm{eGFR}_{\text {cys }}$, $\mathrm{eGFR}_{\text {creat }}$ or $\mathrm{ACR}$ (log-transformed) and the following outcomes were studied: allcause mortality, CVD (CHD + stroke) mortality and incident CVD (non-fatal + fatal). Associations were initially adjusted for age and sex (model 1), followed by additional adjustment for ACR (eGFR and eGFR creat $_{\text {models) or eGFR }}$ (ACR models), (model 2), followed by additional adjustment for CVD risk factors (smoking, systolic blood pressure, diabetes, fasting glucose, total/HDL-cholesterol ratio, and BMI [plus baseline CVD for CVD mortality]), (model 3). Additionally, we inspected eGFR/ACR $\times$ ethnicity and $\mathrm{eGFR} \times \mathrm{ACR}$ interaction terms for each outcome. Cox proportional hazards models were used - the proportional hazards assumption was verified using a formal test of Schoenfeld residuals and by inspection of plots of outcome risk by tertile of CKD marker in each ethnic group. Linearity of associations was checked using the likelihood ratio test, comparing tertiles of exposure versus the linear term. Sub-group analyses were performed by baseline diabetes status. Sensitivity analyses substituted $\mathrm{eGFR}_{\mathrm{MDRD}}$ for

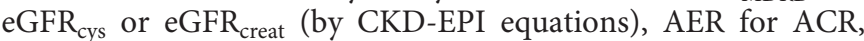
$\mathrm{HbA}_{1 \mathrm{c}}$ for fasting glucose, and diabetes development as a timevarying covariate (no diabetes vs. diagnosis after 2009 vs. diagnosis 1999-2008 vs. diagnosis 1988-2008 vs. baseline diabetes).

Finally, we contrasted the predictive power of $\mathrm{eGFR}_{\mathrm{cys}}$, $\mathrm{eGFR}_{\text {creat }}$, and ACR in turn, for each outcome and in both ethnic groups. We observed the change in the Harrell's C statistic on addition of each CKD marker to an initial model containing age, sex, smoking, systolic blood pressure, diabetes, fasting glucose, total/ HDL-cholesterol ratio, and BMI (plus baseline CVD for CVD mortality). Analyses were conducted in Stata version 14.2.

\section{Results}

A total of 1,116 Europeans and 1,104 South Asians of predominantly Indian heritage had baseline data available on cystatin C, creatinine, and ACR; of these, 976 and 982 respectively had follow-up mortality data, and slightly fewer follow-up cardiovascular morbidity data available (Fig. 1). There were no consistent differences in baseline characteristics by follow-up status (online suppl. Table S2). All-cause mortality rates were lower in South 


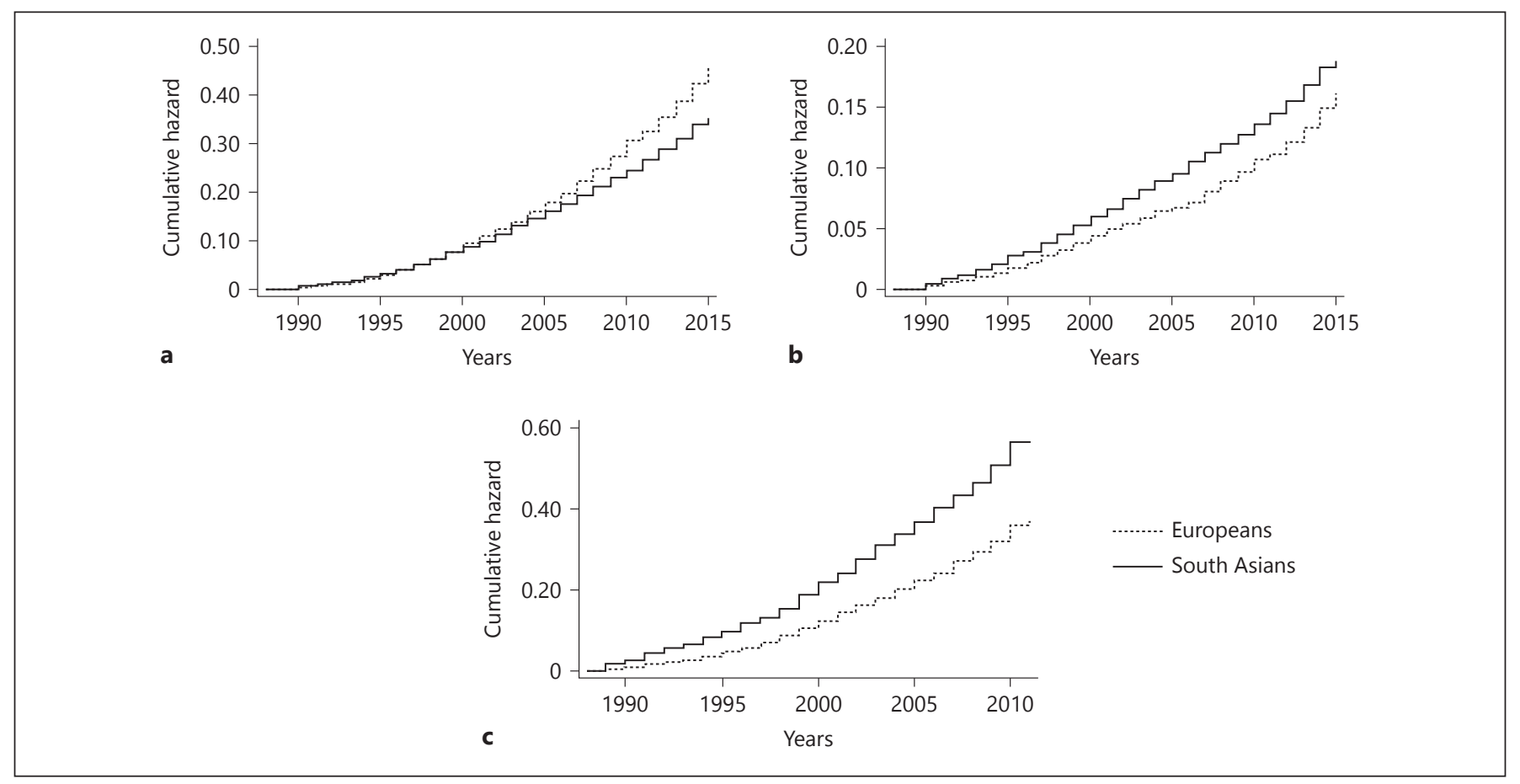

Fig. 2. Cumulative hazards of mortality and morbidity by ethnicity: (a) all-cause mortality, (b) cardiovascular mortality and (c) incident CVD.

Asians than Europeans (298/983 [30\%] vs. 385/978 [39\%] deaths, 13.5 [16.4-20.1] vs. 18.1 [16.4-20.1] per 1,000 person years at risk [PYAR] respectively, age- and sex-adjusted $p=0.22$ ), though South Asians had more CVD-related deaths $(165 / 983$ [17\%] vs. 134/978 [14\%], 7.5 [6.4-8.7] vs. 6.3 [5.3-7.5] per 1000 PYAR, $p<0.001)$ and incident CVD (377/912 [41\%] vs. 283/892 [32\%] events, 25.2 [22.8-27.9] vs. 18.5 [16.4-20.7] per 1000 PYAR, $p<0.001$ ) than Europeans (Fig. 2).

\section{Cross-Sectional Analyses}

South Asians had more adverse levels of cystatin C, $\mathrm{eGFR}_{\text {cys }}$, and ACR than Europeans at baseline, and similar creatinine and eGFR $_{\text {creat }}$ (Table 1). Further, South Asians had worse CVD risk factor profiles than Europeans (bar smoking rates, which were greater in Europeans than South Asians), but there were no ethnic differences in baseline CVD prevalence. No participants were receiving lipid lowering medications at baseline. Similar proportions of Europeans and South Asians had albuminuric CKD (11\% of those with $\mathrm{eGFR}_{\text {cys }}<60 \mathrm{~mL} / \mathrm{min} / 1.73 \mathrm{~m}^{2}$ in the former, and $8 \%$ in the latter, $p=0.67$ ).

Our cross-tabulation of $\mathrm{CKD}$ stages by $\mathrm{eGFR}_{\text {cys }}$ or $\mathrm{eGFR}_{\text {creat }}$ showed that agreement was similar regardless of ethnicity (68.4\% for Europeans vs. $67.8 \%$ for South Asians, $p=0.61$, weighted kappa $=0.41$ for both, online suppl. Table S3). However, for participants who were discordantly classified, more South Asians than Europeans were designated to a more adverse CKD stage when eGFRcys, as opposed to eGFRcreat, was used (19 vs. 9\%, $p<0.001$, online suppl. Fig. S1).

\section{Longitudinal Analyses}

In age- and sex-adjusted models, eGFR was inversely related to mortality and incident CVD in Europeans (Table 2); associations generally persisted after further adjustment for ACR or CVD risk factors, and were similar

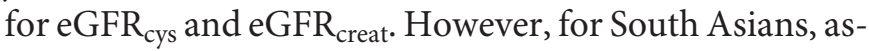
sociations were weaker (e.g., risk factor-adjusted associa-

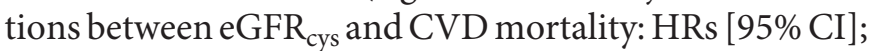
Europeans 0.76 [0.62-0.92] vs. South Asians 0.92 [0.78-1.09], ethnicity interaction $p=0.05)$, or absent when $\mathrm{GFR}_{\text {creat }}$ was used in risk factor-adjusted models. In contrast, age- and sex-adjusted associations between ACR and outcomes were of at least similar or greater magnitude in South Asians than Europeans (e.g., for eGFR $_{\text {cys- }}$ and risk factor-adjusted models of all-cause mortality: Europeans 1.16 [1.06-1.27] vs. South Asians 1.26 [1.14-1.39], ethnic difference $p=0.04$; Table 2). 
Table 1. Baseline characteristics by ethnicity

\begin{tabular}{|c|c|c|c|}
\hline & Europeans & South Asians & $p$ value \\
\hline Number & 1,116 & 1,104 & - \\
\hline Gender, male & $934(84)$ & $881(80)$ & 0.03 \\
\hline Age, years & $54 \pm 7$ & $52 \pm 7$ & $<0.001$ \\
\hline Cystatin C, mg/L & $0.67(0.47-0.90)$ & $0.77(0.55-1.00)$ & $<0.001$ \\
\hline $\mathrm{eGFR}_{\mathrm{cys}}, \mathrm{mL} / \mathrm{min} / 1.73 \mathrm{~m}^{2}$ & $117 \pm 37$ & $107 \pm 37$ & $<0.001$ \\
\hline $\mathrm{eGFR}_{\mathrm{cys}} \leq 60 \mathrm{~mL} / \mathrm{min} / 1.73 \mathrm{~m}^{2}$ & $76(7)$ & $118(11)$ & $<0.001$ \\
\hline Creatinine, $\mu \mathrm{mol} / \mathrm{L}$ & $78(66-90)$ & $76(63-89)$ & 0.51 \\
\hline $\mathrm{eGFR}_{\text {creat }}, \mathrm{mL} / \mathrm{min} / 1.73 \mathrm{~m}^{2}$ & $92 \pm 19$ & $95 \pm 18$ & 0.73 \\
\hline $\mathrm{eGFR}_{\text {creat }} \leq 60 \mathrm{~mL} / \mathrm{min} / 1.73 \mathrm{~m}^{2}$ & $47(4)$ & $40(3)$ & 0.63 \\
\hline $\mathrm{ACR}, \mathrm{mg} / \mathrm{mmol}$ & $0.51(0.38-0.74)$ & $0.54(0.37-0.89)$ & 0.001 \\
\hline Microalbuminuria (ACR 3-30 mg/mmol) & $43(4)$ & $55(5)$ & 0.08 \\
\hline Albumin excretion rate, $\mu \mathrm{g} / \mathrm{min}$ & $3.5(2.5-5.3)$ & $3.4(2.3-5.9)$ & 0.14 \\
\hline Smoking: never/ex/current, \% & $31 / 30 / 39$ & $80 / 11 / 9$ & $<0.001$ \\
\hline $\mathrm{SBP}, \mathrm{mm} \mathrm{Hg}$ & $123 \pm 17$ & $126 \pm 19$ & $<0.001$ \\
\hline On antihypertensive medication & $155(14)$ & $175(16)$ & 0.005 \\
\hline ACE inhibitor use & $6(0.5)$ & $25(2)$ & $<0.001$ \\
\hline Diabetes & $57(5)$ & $227(21)$ & $<0.001$ \\
\hline On antidiabetic medication & $23 / 57(40)$ & $110 / 227(48)$ & 0.17 \\
\hline $\mathrm{HbA}_{\mathrm{lc}}, \mathrm{mmol} / \mathrm{mol}$ & $37(35-40)$ & $40(37-45)$ & $<0.001$ \\
\hline $\mathrm{HbA}_{1 \mathrm{c}}, \%$ & $5.5(5.3-5.8)$ & $5.8(5.6-6.3)$ & $<0.001$ \\
\hline Fasting glucose, $\mathrm{mmol} / \mathrm{L}$ & $5.3(5.0-5.6)$ & $5.5(5.1-6.1)$ & $<0.001$ \\
\hline Total cholesterol: HDL cholesterol ratio & $4.7(3.8-5.8)$ & $4.9(4.1-6.0)$ & $<0.001$ \\
\hline Triglycerides, $\mathrm{mmol} / \mathrm{L}$ & $1.4(1.0-2.1)$ & $1.7(1.2-2.5)$ & $<0.001$ \\
\hline WHR & $0.92 \pm 0.09$ & $0.97 \pm 0.08$ & $<0.001$ \\
\hline BMI, kg/m² & $26.1 \pm 4.0$ & $26.2 \pm 3.8$ & 0.84 \\
\hline Baseline CVD & $116(10)$ & $111(10)$ & 0.26 \\
\hline
\end{tabular}

There was no evidence against linearity of associations for any independent variable. Results were similar when people with baseline diabetes were excluded, or for associations between $\mathrm{GGFR}_{\mathrm{MDRD}}$, cystatin $\mathrm{C}$ or AER and outcomes (online suppl. Table S4), or when substituting $\mathrm{HbAlc}$ for fasting glucose, or considering diabetes as a time-varying covariate (data not shown). There were no statistically significant interactions between eGFR and ACR for any outcome.

We then assessed whether addition of any CKD measure improved a standard risk factor prediction model for all-cause and CVD mortality and incident CVD events (online suppl. Table S5). In Europeans, addition of $\mathrm{eGFR}_{\text {cys }}$ (and to a lesser extent eGFR creat) or ACR modestly increased Harrell's C statistics for mortality and incident CVD. In contrast, for South Asians, increases in the C-statistic were seen on addition of ACR to mortality models, but hardly at all on addition of
$\mathrm{eGFR}_{\text {cys }}$ or eGFR $\mathrm{Great}_{\text {, }}$, and there were no improvements in predictive power for addition of any renal marker to incident CVD models.

\section{Discussion}

We report the following novel findings: first, South Asians (of mostly Indian descent) had more adverse levels of $\mathrm{eGFR}_{\text {cys }}$ than Europeans in this predominantly male sample of middle-aged individuals. Second, agreement between CKD classification by eGFR $\mathrm{R}_{\text {cys }}$ vs. eGFR $\mathrm{R}_{\text {creat }}$ did not differ by ethnicity, though more South Asians than Europeans were re-classified to a more adverse stage when $e^{-G F R} R_{c y s}$ was used. Third, eGFR appeared more strongly related to all-cause and CVD mortality in Europeans, whilst ACR was more strongly related to these outcomes in South Asians. Finally, ad- 
Table 2. Longitudinal associations between baseline eGFR or ACR and mortality or incident CVD, by ethnicity

\begin{tabular}{|c|c|c|c|c|}
\hline CKD measure & Model & Europeans & South Asians & $p$ value ${ }^{\#}$ \\
\hline \multicolumn{5}{|l|}{ All-cause mortality to 2015} \\
\hline \multirow[t]{4}{*}{$\mathrm{eGFR}_{\text {cys }}$} & 0 & $0.72(0.65-0.80)^{* * *}$ & $0.77(0.68-0.87)^{* * *}$ & 0.48 \\
\hline & 1 & $0.83(0.75-0.92)^{* *}$ & $0.91(0.81-1.03)$ & 0.20 \\
\hline & 2 & $0.84(0.76-0.93)^{* *}$ & $0.93(0.82-1.05)$ & 0.29 \\
\hline & 3 & $0.83(0.74-0.93)^{* *}$ & $0.90(0.79-1.02)$ & 0.31 \\
\hline \multirow{4}{*}{$\mathrm{eGFR}_{\text {creat }}(1 \mathrm{SD}$ increase $)$} & 0 & $0.74(0.67-0.81)^{* * *}$ & $0.79(0.71-0.89)^{* * *}$ & 0.29 \\
\hline & 1 & $0.91(0.82-1.02)$ & $1.06(0.93-1.21)$ & 0.04 \\
\hline & 2 & $0.92(0.83-1.03)$ & $1.07(0.94-1.22)$ & 0.10 \\
\hline & 3 & $0.92(0.82-1.03)$ & $1.05(0.92-1.20)$ & 0.11 \\
\hline \multirow[t]{4}{*}{ ACR (1 SD increase) } & 0 & $1.28(1.18-1.39)^{* * *}$ & $1.39(1.27-1.52)^{* * *}$ & 0.18 \\
\hline & 1 & $1.21(1.11-1.31)^{* * *}$ & $1.40(1.27-1.54)^{* * *}$ & 0.009 \\
\hline & 2 & $1.19(1.10-1.30)^{* * *}$ & $1.40(1.27-1.53)^{* * *}$ & 0.008 \\
\hline & 3 & $1.16(1.06-1.27)^{* *}$ & $1.26(1.14-1.39)^{* * *}$ & 0.04 \\
\hline \multicolumn{5}{|l|}{ CVD mortality to 2015} \\
\hline \multirow[t]{4}{*}{$\mathrm{eGFR}_{\text {cys }}$ (1 SD increase) } & 0 & $0.59(0.49-0.71)^{* * *}$ & $0.74(0.63-0.87)^{* * *}$ & 0.07 \\
\hline & 1 & $0.69(0.58-0.83)^{* * *}$ & $0.89(0.76-1.04)$ & 0.02 \\
\hline & 2 & $0.71(0.59-0.85)^{* * *}$ & $0.91(0.78-1.07)$ & 0.04 \\
\hline & 3 & $0.76(0.62-0.92)^{\star *}$ & $0.92(0.78-1.09)$ & 0.05 \\
\hline \multirow[t]{4}{*}{$\mathrm{eGFR}_{\text {creat }}(1 \mathrm{SD}$ increase $)$} & 0 & $0.62(0.53-0.72)^{* * *}$ & $0.82(0.70-0.96)^{*}$ & 0.01 \\
\hline & 1 & $0.75(0.63-0.91)^{* *}$ & $1.13(0.95-1.35)$ & 0.001 \\
\hline & 2 & $0.78(0.65-0.93)^{* *}$ & $1.15(0.96-1.37)$ & 0.002 \\
\hline & 3 & $0.81(0.67-0.99)^{*}$ & $1.18(0.97-1.41)$ & 0.002 \\
\hline \multirow[t]{4}{*}{ ACR (1 SD increase) } & 0 & $1.39(1.22-1.57)^{* * *}$ & $1.51(1.35-1.69)^{* * *}$ & 0.32 \\
\hline & 1 & $1.28(1.13-1.46)^{* * *}$ & $1.52(1.37-1.69)^{* * *}$ & 0.05 \\
\hline & 2 & $1.25(1.10-1.42)^{* *}$ & $1.51(1.36-1.69)^{* * *}$ & 0.05 \\
\hline & 3 & $1.24(1.08-1.42)^{* *}$ & $1.39(1.25-1.57)^{* * *}$ & 0.23 \\
\hline \multicolumn{5}{|c|}{ Incident CVD (excludes those with baseline CVD) to 2011} \\
\hline \multirow[t]{4}{*}{$\mathrm{eGFR}_{\text {cys }}(1 \mathrm{SD}$ increase) } & 0 & $0.75(0.66-0.84)^{* * *}$ & $0.84(0.75-0.94)^{* *}$ & 0.18 \\
\hline & 1 & $0.81(0.72-0.92)^{* *}$ & $0.91(0.81-1.01)$ & 0.09 \\
\hline & 2 & $0.82(0.72-0.93)^{* *}$ & $0.91(0.81-1.02)$ & 0.12 \\
\hline & 3 & $0.87(0.77-0.99)^{*}$ & $0.92(0.82-1.03)$ & 0.30 \\
\hline \multirow[t]{4}{*}{$\mathrm{eGFR}_{\text {creat }}(1 \mathrm{SD}$ increase $)$} & 0 & $0.76(0.68-0.85)^{* * *}$ & $0.87(0.78-0.97)^{*}$ & 0.09 \\
\hline & 1 & $0.86(0.76-0.97)^{*}$ & $1.00(0.89-1.13)$ & 0.01 \\
\hline & 2 & $0.87(0.76-0.98)^{*}$ & $1.00(0.89-1.13)$ & 0.02 \\
\hline & 3 & $0.92(0.80-1.05)$ & $1.02(0.90-1.16)$ & 0.03 \\
\hline \multirow[t]{4}{*}{ ACR (1 SD increase) } & 0 & $1.19(1.07-1.32)^{* *}$ & $1.18(1.07-1.30)^{* *}$ & 0.96 \\
\hline & 1 & $1.14(1.03-1.26)^{*}$ & $1.20(1.09-1.33)^{* * *}$ & 0.40 \\
\hline & 2 & $1.13(1.02-1.24)^{*}$ & $1.20(1.09-1.32)^{* * *}$ & 0.36 \\
\hline & 3 & $1.08(0.97-1.21)$ & $1.08(0.97-1.20)$ & 0.78 \\
\hline
\end{tabular}

ACR log-transformed.

Data are HR (95\% CI), ${ }^{* * *} p<0.001,{ }^{* *} p<0.01,{ }^{*} p<0.05,{ }^{*} p=p$ value for ethnicity $\times$ CKD measure interaction term.

Model 0: unadjusted, model 1: age + sex, model 2: age + sex + ACR/eGFR cys, model 3: age + sex + ACR/eGFR + smoking $+\mathrm{SBP}+$ diabetes + fasting glucose $+\mathrm{TC} / \mathrm{HDL}+\mathrm{BMI}$ (+ baseline CVD for cardiovascular mortality).

Includes all for whom cystatin $\mathrm{C}$, creatinine and $\mathrm{ACR}$ available.

$\mathrm{ACR}$, albumin-creatinine ratio; CVD, cardiovascular disease; $\mathrm{CKD}$, chronic kidney disease. 
dition of eGFR and ACR to standard CVD risk factor models improved the predictive power for mortality and CVD events in Europeans, but only addition of ACR to mortality models gave any improvement for South Asians.

Our observation of lower eGFR $\mathrm{Cys}_{\text {s }}$ and higher ACR in South Asians than Europeans is in keeping with the disproportionate rates of end-stage renal failure experienced by UK South Asians, likely mediated by the much greater diabetes prevalence in the former group $[6,12,13,27]$. Previous studies reporting eGFR comparisons in these groups have used the MDRD creatinine-based estimating equation [23] and found no ethnic differences in eGFR [6-10] although most, but not all [14], report higher levels of albuminuria in South Asians with $[7,9,28]$ and without diabetes $[6,8,10,29]$. We also found no ethnic differences when creatinine-based eGFR measures were compared.

In our comparison of the agreement between $\mathrm{CKD}$

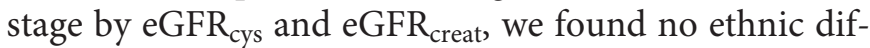
ference in the overall agreement, though South Asians were more likely to be re-classified to a more adverse CKD stage by eGFR $\mathrm{R}_{\text {cys }}$, in keeping with the slightly more adverse longitudinal associations we found between $\mathrm{eGFR}_{\text {cys }}$ than eGFR $\mathrm{Great}_{\text {and outcomes. }}$ and

We believe our study to be the first to compare South Asians and Europeans with regard to eGFR $\mathrm{Cys}_{\text {cys }}$ levels and their associations with cardiometabolic risk factors and CVD outcomes.

Lower eGFR, however defined, was more strongly associated with mortality and incident CVD in Europeans than South Asians. The only other study (of Canadian primary care records) addressing this comparison showed no ethnic differences in associations between eGFR and mortality/CVD outcomes between South Asians and Europeans [8], though eGFR $\mathrm{MDRD}_{\mathrm{M}}$ was used, the study population was younger than ours and bias may have been introduced by designating ethnicity on surname alone. ACR was more strongly associated with longitudinal (mortality/CVD) outcomes in South Asians than Europeans. Furthermore, in prediction models of mortality and CVD outcomes, both eGFR and ACR led to small improvements in predictive ability in Europeans, but only ACR increased the predictive power for South Asians, and only for mortality models.

CKD-EPI equations have not been validated in UK/US South Asian migrant populations [30], therefore a possible explanation for the weaker associations seen between eGFR and outcomes in South Asians compared to
Europeans is poor correlation between eGFR and mGFR in this population. However, recent data from India suggest a good correlation between CKD-EPI eGFR $\mathrm{Cys}_{\text {- }}$ albeit not CKD-EPI eGFR creat $_{\text {- }}$ and mGFR [31], corroborating findings in South Asian migrant groups elsewhere [32-34]. It has been argued previously that cystatin Cbased equations should be more accurate than creatininebased ones in ethnic minority groups [18, 20, 32, 33], since cystatin $\mathrm{C}$ is considered to be independent of muscle mass and dietary protein intake, which may differ by ethnic group $[15,16]$.

Another potential explanation of our findings is that eGFR and ACR represent complementary manifestations of kidney damage [35]; eGFR may be a superior indicator of cardiometabolic health in Europeans, and ACR in South Asians. The role of eGFR in the pathogenesis of CVD is unclear; a recent Mendelian randomization study was unable to establish conclusively whether GFR had a direct effect on CHD [36]. Some authors argue that decline in eGFR merely represents duration of exposure to traditional CVD risk factors, that is, it is a "parallel" risk factor [37]. In contrast, it has been suggested that albuminuria is an early marker of more aggressive damage to susceptible circulations, not just of glomerular damage [38], and that albuminuria and CVD are linked by a common pathway of microvascular and endothelial dysfunction [39-41].

Mechanistic pathways linking CKD markers to mortality/CVD outcomes may differ by biomarker and ethnicity, such that in Europeans (with their much lower prevalence of diabetes and hyperglycemia) the predominant pathway may be due to aging, of which eGFR may be the superior indicator. In South Asians, on the contrary, baseline measures of glycemia were more strongly associated with ACR, suggesting a predominant pathway involving glycemia and microcirculatory/endothelial dysfunction, of which ACR is the superior indicator [42]. The etiology of these ethnic differences in CKD pathways may relate to genetic, epigenetic or other influences acting over the life course [41].

\section{Strengths and Limitations}

This longitudinal study is unique in comparing associations between eGFRcys or ACR and mortality or incident CVD in Europeans and South Asians, with excellent follow-up rates and adequate power to show ethnic differences. By studying data from ethnic groups with different levels of CVD risk factors, we have provided fresh mechanistic insights into pathways linking CKD and CVD. A key strength was the use of cystatin C for eGFR equations, a 
filtration marker generally considered to be independent of body composition and diet [21]. Whilst a single CKD measurement may not adequately represent lifetime exposure, imprecision in the measurement of exposures is unlikely to obscure ethnic differences. However, data were not available for rates of decline of CKD markers, which may be more rapid in South Asians than Europeans [6, 9], and is an important predictor of disease outcomes [43]. Equally, no data were available on the duration or etiology of kidney injury at baseline, and there were too few renal events for analyses at follow-up. Potential confounders may have varied over time, especially with regards to lifestyle, weight change, dietary composition, lipid levels, and use of statins, anti-hypertensives, and anti-diabetic medication. Allowing for diabetes as a time-varying covariate, however, did not alter results and we have shown than baseline antihypertensive use was greater in South Asians, but unfortunately do not have adequate data to further explore this conjecture. Finally, the UK South Asian population in our study was of predominantly Indian origin, thus caution should be exercised in applying findings to other South Asian sub-groups, who may differ in their diet, risk factors, and body habitus.

In this longitudinal comparison of UK ethnic groups, we have shown that $\mathrm{GFR}_{\mathrm{cys}}$ was lower in South Asians than Europeans, while eGFR creat was similar in the 2 ethnic groups. In contrast, ACR levels were higher and more strongly related to CVD outcomes in South Asians than Europeans. Both markers improved the prediction of outcomes for Europeans, but for South Asians only ACR enhanced predictive capability of models. These findings suggest mechanistic differences in how CKD markers relate to mortality and CVD in different ethnic groups. If corroborated, our results indicate that ACR may have greater utility compared with eGFR in the prediction of CVD risk and mortality in South Asians.

\section{Acknowledgements}

The authors thank all members of the SABRE group for contributions to study design, management, data collection, and analyses. Hospital Episode Statistics to 2011 were provided by NHS Digital (formerly the Health and Social Care Information Centre). We are grateful to the UK Office for National Statistics for the provision of mortality data and we declare that those who carried out the original collection and analysis of those data bear no responsibility for their further analysis or interpretation in this manuscript.

\section{Disclosure Statement}

The authors have no conflicts of interest to declare.

\section{Funding Sources}

The study was funded at baseline by the UK Medical Research Council and Diabetes UK. Follow-up studies have been funded by the Wellcome Trust, British Heart Foundation and Diabetes UK. A.D.H. and N.C. received support from the National Institute for Health Research University College London Hospitals Biomedical Research Centre. A.D.H. and N.C. work in a unit that receives support from the UK Medical Research Council (MC_UU_12019/1). Support has also been provided at follow-up by the North and West London and Central and East London National Institute of Health Research Clinical Research Networks.

\section{Author Contributions}

All authors contributed to study design and interpretation. S.V.E. performed statistical analyses and wrote the first draft of the manuscript. T.T. was involved in data collection, analysis, and processing. T.T., N.S., P.I.W., A.D.H., and N.C. read, commented on, and approved the final manuscript. S.V.E. is the guarantor of this work and, as such, had full access to all the data in the study and takes responsibility for the integrity of the data and the accuracy of the data analysis.

\section{References}

1 Go AS, Chertow GM, Fan D, McCulloch CE, Hsu CY. Chronic kidney disease and the risks of death, cardiovascular events, and hospitalization. N Engl J Med. 2004 Sep;351(13): 1296-305

2 Matsushita $\mathrm{K}$, van der Velde M, Astor BC, Woodward M, Levey AS, de Jong PE, et al. Association of estimated glomerular filtration rate and albuminuria with all-cause and cardiovascular mortality in general population cohorts: a collaborative meta-analysis. Lancet. 2010 Jun;375(9731):2073-81.
3 Fraser SD, Aitken G, Taal MW, Mindell JS, Moon G, Day J, et al. Exploration of chronic kidney disease prevalence estimates using new measures of kidney function in the health survey for England. PLoS One. 2015 Feb; 10(2):e0118676.

4 Office of National Statistics. Ethnicity and national identity in England and Wales. 2012. [cited 2017 21st August]. Available from: https://www.ons.gov.uk/ peoplepopulationandcommunity/culturalidentity/ethnicity/articles/ethnicityandna- tionalidentityinenglandandwales/ 2012-12-11.

5 US census bureau. 2010. [cited 2017 21st August]. Available from: https://www.census. gov/newsroom/releases/archives/2010_census/cb12-cn22.html.

6 Barbour SJ, Er L, Djurdjev O, Karim M, Levin A. Differences in progression of CKD and mortality amongst Caucasian, Oriental Asian and South Asian CKD patients. Nephrol Dial Transplant. 2010 Nov;25(11): 3663-72. 
7 Bhalla V, Zhao B, Azar KM, Wang EJ, Choi S, Wong EC, et al. Racial/ethnic differences in the prevalence of proteinuric and nonproteinuric diabetic kidney disease. Diabetes Care. 2013 May;36(5):1215-21.

8 Conley J, Tonelli M, Quan H, Manns BJ, Palacios-Derflingher L, Bresee LC, et al.; Alberta Kidney Disease Network. Association between GFR, proteinuria, and adverse outcomes among White, Chinese, and South Asian individuals in Canada. Am J Kidney Dis. 2012 Mar;59(3):390-9.

9 Dreyer G, Hull S, Mathur R, Chesser A, Yaqoob MM. Progression of chronic kidney disease in a multi-ethnic community cohort of patients with diabetes mellitus. Diabet Med. 2013 Aug;30(8):956-63.

10 Jesky M, Lambert A, Burden AC, Cockwell P. The impact of chronic kidney disease and cardiovascular comorbidity on mortality in a multiethnic population: a retrospective $\mathrm{Co}_{-}$ hort study. BMJ Open. 2013 Dec;3(12): e003458.

11 Ball S, Lloyd J, Cairns T, Cook T, Palmer A, Cattell V, et al. Why is there so much endstage renal failure of undetermined cause in UK Indo-Asians? QJM. 2001 Apr;94(4):18793.

12 Renal register. Thirteenth annual report. 2010. [cited 2017 August 7th]. Available from: https://www.renalreg.org/reports/2010-thethirteenth-annual-report/.

13 Roderick PJ, Raleigh VS, Hallam L, Mallick NP. The need and demand for renal replacement therapy in ethnic minorities in England. J Epidemiol Community Health. 1996 Jun; 50(3):334-9.

14 Tillin T, Forouhi N, McKeigue P, Chaturvedi N. Microalbuminuria and coronary heart disease risk in an ethnically diverse UK population: a prospective cohort study. J Am Soc Nephrol. 2005 Dec;16(12):3702-10.

15 Eastwood SV, Tillin T, Wright A, Mayet J, Godsland I, Forouhi NG, et al. Thigh fat and muscle each contribute to excess cardiometabolic risk in South Asians, independent of visceral adipose tissue. Obesity (Silver Spring). 2014 Sep;22(9):2071-9.

16 Eriksen A, Tillin T, O'Connor L, Brage S, Hughes A, Mayet J, et al. The impact of health behaviours on incident cardiovascular disease in Europeans and South Asians-a prospective analysis in the UK SABRE study. PLoS One. 2015 Mar;10(3):e0117364.

17 Inker LA, Schmid CH, Tighiouart H, Eckfeldt JH, Feldman HI, Greene T, et al.; CKD-EPI Investigators. Estimating glomerular filtration rate from serum creatinine and cystatin C. N Engl J Med. 2012 Jul;367(1):20-9.

18 Pottel H, Hoste L, Delanaye P, Cavalier E, Martens F. Demystifying ethnic/sex differences in kidney function: is the difference in (estimating) glomerular filtration rate or in serum creatinine concentration? Clin Chim Acta. 2012 Oct;413(19-20):1612-7.

19 Tillin T, Forouhi NG, McKeigue PM, Chaturvedi N; SABRE Study Group. Southall
And Brent REvisited: cohort profile of SABRE, a UK population-based comparison of cardiovascular disease and diabetes in people of European, Indian Asian and African Caribbean origins. Int J Epidemiol. 2012 Feb;41(1): $33-42$.

20 National Institute of Health and Clinical Excellence. CG182 CKD in adults: assessment and management. 2014. [cited 2017 August 10th]. Available from: https://www.nice.org. uk/guidance/cg182/chapter/1-Recommend ations\#investigations-for-chronic-kidneydisease-2.

21 Lopez-Giacoman S, Madero M. Biomarkers in chronic kidney disease, from kidney function to kidney damage. World J Nephrol. 2015 Feb;4(1):57-73.

22 Shlipak MG, Matsushita K, Ärnlöv J, Inker LA, Katz R, Polkinghorne KR, et al.; CKD Prognosis Consortium. Cystatin C versus creatinine in determining risk based on kidney function. N Engl J Med. 2013 Sep;369(10): 932-43.

23 Levey AS, Bosch JP, Lewis JB, Greene T, Rogers N, Roth D; Modification of Diet in Renal Disease Study Group. A more accurate method to estimate glomerular filtration rate from serum creatinine: a new prediction equation. Ann Intern Med. 1999 Mar;130(6):461-70.

24 Kearney EM, Mount JN, Watts GF, Slavin BM, Kind PR. Simple immunoturbidimetric method for determining urinary albumin at low concentrations using Cobas-Bio centrifugal analyser. J Clin Pathol. 1987 Apr;40(4): 465-8.

25 World Health Organisation. Definition, diagnosis and classification of diabetes mellitus and its complications. Part 1: diagnosis and classification of diabetes mellitus. 1999. [cited 2017 August 10th]. Available from: http:// apps.who.int/iris/handle/10665/66040.

26 Sever PS, Dahlöf B, Poulter NR, Wedel H, Beevers G, Caulfield M, et al. Rationale, design, methods and baseline demography of participants of the Anglo-Scandinavian Cardiac Outcomes Trial. ASCOT investigators. J Hypertens. 2001 Jun;19(6):1139-47.

27 Pazianas M, Eastwood JB, MacRae KD, Phillips ME. Racial origin and primary renal diagnosis in 771 patients with end-stage renal disease. Nephrol Dial Transplant. 1991;6(12): 931-5.

28 Mather HM, Chaturvedi N, Kehely AM. Comparison of prevalence and risk factors for microalbuminuria in South Asians and Europeans with type 2 diabetes mellitus. Diabet Med. 1998 Aug;15(8):672-7.

29 Fischbacher CM, Bhopal R, Rutter MK, Unwin NC, Marshall SM, White M, et al. Microalbuminuria is more frequent in South Asian than in European origin populations: a comparative study in Newcastle, UK. Diabet Med. 2003 Jan;20(1):31-6.

30 Lamb EJ, Brettell EA, Cockwell P, Dalton N, Deeks JJ, Harris K, et al.; eGFR-C study group. The eGFR-C study: accuracy of glomerular filtration rate (GFR) estimation us- ing creatinine and cystatin $\mathrm{C}$ and albuminuria for monitoring disease progression in patients with stage 3 chronic kidney diseaseprospective longitudinal study in a multiethnic population. BMC Nephrol. 2014 Jan; 15(1):13

31 Kumar V, Yadav AK, Yasuda Y, Horio M, Kumar V, Sahni N, et al. Existing creatininebased equations overestimate glomerular filtration rate in Indians. BMC Nephrol. 2018 Feb;19(1):22.

32 Hafeez AR, Idrees MK, Akhtar SF. Accuracy of GFR estimation formula in determination of glomerular filtration rate in kidney donors: comparison with $24 \mathrm{~h}$ urine creatinine clearance. Saudi J Kidney Dis Transpl. 2016 Mar; 27(2):320-5

33 Jessani S, Levey AS, Bux R, Inker LA, Islam M, Chaturvedi N, et al. Estimation of GFR in South Asians: a study from the general population in Pakistan. Am J Kidney Dis. 2014 Jan; 63(1):49-58.

34 Teo BW, Xu H, Wang D, Li J, Sinha AK, Shuter B, et al. Estimating glomerular filtration rates by use of both cystatin $\mathrm{C}$ and standardized serum creatinine avoids ethnicity coefficients in Asian patients with chronic kidney disease. Clin Chem. 2012 Feb;58(2): $450-7$.

35 de Zeeuw D, Parving HH, Henning RH. Microalbuminuria as an early marker for cardiovascular disease. J Am Soc Nephrol. 2006 Aug; 17(8):2100-5.

36 Charoen P, Nitsch D, Engmann J, Shah T, White J, Zabaneh D, et al.; UCLEB Consortium. Mendelian Randomisation study of the influence of eGFR on coronary heart disease. Sci Rep. 2016 Jun;6(1):28514.

37 Chang A, Kramer H. Should eGFR and albuminuria be added to the Framingham risk score? Chronic kidney disease and cardiovascular disease risk prediction. Nephron Clin Pract. 2011;119(2):c171-7.

38 Ito S, Nagasawa T, Abe M, Mori T. Strain vessel hypothesis: a viewpoint for linkage of albuminuria and cerebro-cardiovascular risk. Hypertens Res. 2009 Feb;32(2):115-21.

39 Currie G, Delles C. Proteinuria and its relation to cardiovascular disease. Int J Nephrol Renovasc Dis. 2013 Dec;7:13-24.

40 Rabelink TJ, de Zeeuw D. The glycocalyxlinking albuminuria with renal and cardiovascular disease. Nat Rev Nephrol. 2015 Nov; 11(11):667-76.

41 Thomas MC, Brownlee M, Susztak K, Sharma K, Jandeleit-Dahm KA, Zoungas S, et al. Diabetic kidney disease. Nat Rev Dis Primers. 2015 Jul;1:15018.

42 Abdelhafiz AH, Ahmed S, El Nahas M. Microalbuminuria: marker or maker of cardiovascular disease. Nephron, Exp Nephrol. 2011;119(suppl 1):e6-10.

43 Coresh J, Turin TC, Matsushita K, Sang Y, Ballew SH, Appel LJ, et al. Decline in estimated glomerular filtration rate and subsequent risk of end-stage renal disease and mortality. JAMA. 2014 Jun;311(24):2518-31. 